\title{
Habilitação, reabilitação e inclusão: o que os sujeitos surdos pensam do trabalho fonoaudiológico?
}

\author{
Habilitation, rehabilitation and inclusion: what is the Deaf perception \\ about speech therapy work?
}

\section{Habilitación, rehabilitación e inclusión: ¿cuál es la percepción de los sordos sobre el trabajo de la terapia del habla?}

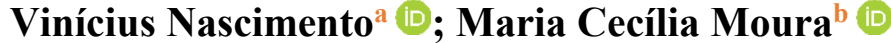 \\ ${ }^{a}$ Doutor e Mestre em Linguística Aplicada e Estudos da Linguagem (PUC-SP) e Bacharel em Fonoaudiologia (PUC-SP). Professor Adjunto do Departamento de Psicologia no curso de Bacharelado em Tradução e Interpretação em Libras e Língua Portuguesa da Universidade Federal de São Carlos (UFSCar). São Carlos, SP, Brasil - E-mail: nascimento_v@ufscar.br \\ ${ }^{b}$ Doutora em Psicologia Social e Mestre em Distúrbios da Comunicação pela PUC-SP. Fonoaudióloga pela mesma instituição. Professora da Faculdade de Ciências Humanas e da Saúde no Curso de Fonoaudiologia da Pontifícia Universidade Católica de São Paulo. São Paulo, SP, Brasil - E-mail: alce55@uol.com.br}

Resumo: Este trabalho analisa a representação que os sujeitos Surdos possuem do fonoaudiólogo e do trabalho na reabilitação em diferentes abordagens utilizadas por estes profissionais. Foram entrevistados dezesseis sujeitos Surdos por meio de filmagem com câmera digital e suas entrevistas foram traduzidas, transcritas e analisadas posteriormente por meio da proposta de Bardin (1977). Os resultados mostram que o fonoaudiólogo é visto pelos Surdos como aquele que pode possibilitar o acesso à linguagem oral para que eles se comuniquem com ouvintes que não saibam Libras. O corpus também mostra uma mudança política do Surdo frente a fala, visto que no discurso dos entrevistados a linguagem oral aparece como uma necessidade para a comunicação com sujeitos ouvintes que não saibam língua de sinais e não mais como uma imposição por parte da família.

Palavras-chave: Fonoaudiologia. Reabilitação. Surdos. Libras. Abordagem bilíngue.

\begin{abstract}
This paper analyzes the representation that Deaf individuals have about the speech therapists working in rehabilitation and the different approaches used by these professionals. Sixteen Deaf individuals were interviewed and video recorded. The interviews were then translated, transcribed and later analyzed using Bardin proposal (1977). The results show that the speech therapist is seen by the Deaf as one that can provide them access to the oral language so they can communicate with hearing people who do not know Brazilian Sign Language (Libras). The corpus also show a change in the policy of the Deaf towards speech, since in the interviewees' discourse, the oral language appears as a necessity for communication with individuals who are hearing and don't know sign language and not as an imposition made by the family.
\end{abstract}

Keywords: Speech therapy. Rehabilitation. Deaf. Brazilian sign language. Bilingual approach.

Resumen: Este artículo analiza la representación que los individuos Sordos tienen sobre los terapeutas del habla que trabajan en rehabilitación y los diferentes enfoques utilizados por estos profesionales. Dieciséis individuos Sordos fueron entrevistados y grabados en video. Las entrevistas fueron luego traducidas, transcritas y entonces analizadas utilizando la obra, forneça um link para a licença, e indicar se foram feitas alterações. 
propuesta de Bardin (1977). Los resultados muestran que los Sordos consideran que el terapeuta del habla puede brindarles acceso a la lengua oral para que puedan comunicarse con personas oyentes que no conocen la Lengua de Señas Brasileña (Libras). El corpus también muestra un cambio en la política de los Sordos hacia el habla, ya que en el discurso de los entrevistados, el lenguaje oral aparece como una necesidad para la comunicación con las personas que escuchan y no saben el lenguaje de señas y no como una imposición hecha por la familia.

Palabras clave: Terapia del habla. Rehabilitación. Sordos. Lengua de señas brasileña. Enfoque bilingüe

\section{Como citar o artigo:}

NASCIMENTO, V. MOURA, M. C. Habilitação, reabilitação e inclusão: o que os sujeitos surdos pensam do trabalho fonoaudiológico? Revista de Ciências Humanas, v.52. 2018. DOI: 10.5007/2178-4582.2018.49807

\section{INTRODUÇÃO}

Atualmente, no Brasil, o fonoaudiólogo é o profissional habilitado para trabalhar com a surdez e a deficiência auditiva do diagnóstico, que é feito em parceria com o médico otorrinolaringologista, até reabilitação de indivíduos que as possuem, responsabilizando-se, dentre outros aspectos, pelo acolhimento e orientação de pacientes e familiares. No caso do diagnóstico em crianças, o fonoaudiólogo atua diretamente com os pais e/ou cuidadores visando, com isso, propiciar à criança a aquisição de uma língua em que ela se inscreva como sujeito e tenha, então, um bom desenvolvimento biopsicossocial.

No entanto, a surdez e a deficiência auditiva estiveram, durante algum tempo, sob a responsabilidade da medicina, no que tange ao diagnóstico e intervenção, e da educação, no tange à reabilitação, e só começou a deslocar-se destes campos desde o início da prática fonoaudiológica no Brasil no final da década de 1950. Este deslocamento para o campo de trabalho do fonoaudiólogo se deve a um conjunto de fatores históricos, acadêmicos e sociais que fizeram com que o diagnóstico, a reabilitação e o acompanhamento do sujeito $\operatorname{Surdo}^{1}$ ficasse sob a responsabilidade deste profissional.

Nesse sentido, embora a fonoaudiologia seja uma área do conhecimento ligada ao campo da saúde, ela mobiliza, do diagnóstico à inclusão social do surdo, diferentes aspectos e conceitos ligados às Ciências Humanas e Sociais, haja vista que o processo educacional dos surdos também é orientado e, na maioria das vezes, direcionado pelo fonoaudiólogo. Segundo Nascimento e Brait (2016), pela necessidade de reconfigurar seu objeto, a fonoaudiologia passou a dialogar com outros campos, de maneira especial, com uma certa Linguística e com a Psicanálise ampliando, assim, o seu objeto de trabalho e estudo. Os autores destacam que por trabalhar, na clínica, com a linguagem em suas diferentes dimensões, os fonoaudiólogos ancoram sua atuação e prática para além dos aspectos

\footnotetext{
${ }^{1}$ O termo "Surdo" será grafado em maiúscula para diferenciar de "surdo". O primeiro se refere a um grupo particular de pessoas que compartilham uma língua e uma cultura e o segundo se refere à condição audiológica de não ouvir (PADDEN; HUMPHRIES, 1988). Segundo Moura (2000) "Surdo" se refere também àquele que ainda que não inserido na comunidade Surda teria o direito de ali estar.
} 
biológicos e mobilizam conceitos necessários e importantes à condição biopsicossocial dos sujeitos que constituem público-alvo de sua atuação.

Historicamente, a reabilitação de sujeitos Surdos esteve a cargo da educação especial que realizava, em seu espaço pedagógico, o ensino da fala a esses sujeitos, considerando as suas possibilidades de aprendizado dessa modalidade de comunicação por meio de exercícios articulatórios e de compensação auditiva (BALIEIRO; FICKER, 1997). Esse foi um trabalho incentivado pelo governo que promovia a formação de professores primeiramente pelos cursos ministrados no Instituto Nacional de Educação de Surdos (INES) (MOURA, 2000) como por cursos ministrados pelo Centro Nacional de Educação Especial (CENESP) na década de 1970 (BRASIL, 1979).

No entanto, quando direcionamos nosso olhar para além da história da educação dos Surdos, encontramos a reabilitação da surdez feita sob outras perspectivas. Segundo Coutinho (2008), as primeiras referências sobre a existência dos Surdos e de sua comunicação surgem dentro dos dois principais campos do pensamento humano: a filosofia e a religião. $\mathrm{O}$ autor ainda salienta que foi a partir destas perspectivas que os Surdos foram narrados, excluídos e incluídos na sociedade. A concepção da fala enquanto chave da razão e da audição como porta de ativação do pensamento já era mencionada por Aristóteles no século IV a. C. e, de acordo com o autor, reflete o posicionamento religioso dos gregos na época em que a defesa da fala como origem da criação e divindade era marcante e que às pessoas Surdas deveria ser negada a instrução, pois o decreto dos deuses não poderia ser mudado, visto que eles eram considerados incapazes de falar.

No Brasil, a educação de Surdos começou com a vinda do professor Surdo E. Hernest Huet no ano de 1855. Huet era ex-aluno de Laurent Clerc, também professor Surdo, na França, e foi o fundador do Instituto Nacional de Surdos-Mudos, hoje Instituto Nacional de Educação de Surdos (INES) que teve apoio de Dom Pedro II para o estabelecimento do Instituto (MOURA, 2000). O currículo proposto por Huet era composto pelas disciplinas de português, aritmética, história, geografia, escrituração mercantil, linguagem articulada, leitura sobre os lábios e doutrina cristã (LULKIN, 1998; MOURA, 2000). A oralidade estava em evidência na inicial educação dos Surdos brasileiros. Os sucessores de Huet no Instituto priorizaram a educação por meio da palavra articulada e quase todos foram à Europa verificar como era feita a educação de Surdos trazendo os modelos para o Brasil. Esses modelos eram resultantes do famoso, e decisivo, congresso de Milão de 1880 que priorizou a linguagem falada como metodologia a ser usada na educação de Surdos em todo o mundo.

Durante o século XIX, esta educação esteve diluída na preocupação da homogeneização da língua pátria e da destituição dos resquícios patológicos e desviantes desta língua porque se priorizava a criação de um estado nacional (NASCIMENTO, 2002). Decerto que a educação de surdos era vista 
como um tropeço para a homogeneização devido o pensamento ideológico de unificação da língua utilizada pela nação ser algo dominante na época.

A necessidade de igualizar as falas desviantes e tornar a língua unificada foram impulsionadas pela preocupação de conter possíveis perigos trazidos pelos imigrantes estrangeiros à língua falada no Brasil. Esse pensamento impulsionou campanhas, em todo território nacional, proclamando que essas influências se caracterizavam como patologia social para a língua (BERBERIAN, 1995). As escolas, que foram os locais escolhidos para tratar esses desvios da fala, receberam médicos e professores que, posteriormente, foram substituídos por ortofonistas.

Segundo Nascimento (2002), a necessidade de homogeneização da língua nacional deu origem à criação de uma profissão que olhasse para a língua de maneira exclusiva, pois este olhar, até então, era realizado, como parte da política higienista do governo nas décadas de 1950 e 1960 , por professoras cursando pedagogia ou psicologia. Por esses motivos, na década de 1960, os primeiros cursos de fonoaudiologia do Brasil foram criados. A autora salienta que essa profissão sempre foi pautada em uma concepção reabilitadora, ou seja, que se propõe a colocar dentro do padrão de normalidade aquilo que é desviante.

A surdez, enquanto alteração orgânica que impede a aquisição da língua majoritária em sua modalidade oral, sempre foi abordada pela fonoaudiologia a partir de uma óptica patológica, o que fez com que estes profissionais tivessem a preocupação em produzir, então, formas reabilitadoras das funções auditivas com o objetivo de adequar o sujeito Surdo às convenções do padrão de normalidade ouvinte. Por esse motivo as pessoas com deficiência auditiva ${ }^{2}$ sempre foram vistas como incapazes de estarem no convívio social, pelo fato de apresentarem uma característica que impossibilita a comunicação por meio da oralidade, ou seja, a audição.

Porém, com as pesquisas e estudos teóricos, iniciados por Willian Stokoe, na década de 1960, sobre as línguas de sinais, comprovando seu status linguístico e sua legitimação enquanto línguas naturais somado aos movimentos multiculturais que tomaram força na década de 80 , do século XX (MOURA, 2000) mudou-se o panorama da educação e da reabilitação dos Surdos. Esses movimentos levaram esses sujeitos a iniciarem um movimento em prol do reconhecimento da importância de sua língua natural nos processos educativos, bem como os aspectos como identidade, comunidade e cultura Surdas. Assim, um novo cenário começou a ser delineado para a fonoaudiologia brasileira na atuação com sujeitos Surdos.

\footnotetext{
${ }^{2} \mathrm{O}$ termo deficiência auditiva será usado no sentido original de seu significado etimológico, déficit na audição, e não no estigma que esse termo imprime nos sujeitos que a possuem, tal como propõe Goffman (1988), no qual são incapazes de, ou impossibilitados de realizar por causa de.
} 
Muitas foram as ações, impulsionadas por esse movimento, para promover mudanças reais na educação e reabilitação de Surdos. Um dos resultados dessas ações foi o reconhecimento da Libras, por meio da Lei n. 10.436, de 24 de abril de 2002 (BRASIL, 2002), como forma de comunicação e expressão da comunidade Surda brasileira e a sua regulamentação por meio do Decreto n. 5.626, de 22 de dezembro de 2005 (BRASIL, 2005), que determinou sua inclusão como disciplina obrigatória nas matrizes curriculares nos cursos de fonoaudiologia, formação de professores em nível de magistério, na educação superior e nas diferentes modalidades de licenciatura.

A inserção da disciplina de Libras em cursos de fonoaudiologia foi, sem dúvidas, um avanço para reabilitação das pessoas Surdas que poderão ser observadas para além da dimensão biológica de não-ouvir. O espaço da Libras nesses cursos promove reflexões sobre a condição sociolinguística minoritária dos surdos, isto é, como sujeitos falantes de uma língua diferente da língua portuguesa e que podem constituir, a partir desse sistema linguístico, sua identidade e subjetividade. Nessa direção, Guarinello et al. (2013), em estudo sobre o impacto da inserção da disciplina de Libras em cursos de fonoaudiologia, destacam que, mesmo com uma carga horária insuficiente para a aprendizagem da língua, há uma sensibilização e mudança de postura dos estudantes frente ao Surdo e a sua língua. As autoras salientam, ainda que, há de se pensar na ampliação desses espaços em cursos de formação de fonoaudiólogos para que práticas fonoaudiológicas bilíngues, clínicas e educacionais dirigidas a sujeitos surdos sejam ampliadas e promovidas.

Nessa mesma direção, Souza e Porrozzi (2009, p. 45) destacam que a formação em Libras deveria alcançar todos os profissionais do campo da saúde e das esferas públicas de atendimento aos cidadãos:

\begin{abstract}
ao incorporar a LIBRAS como disciplina regular em grades curriculares dos cursos, a mesma seria alvo de estudos acadêmicos que iriam contribuir para o seu aprimoramento didáticocientífico em níveis que proporcionariam um avanço significativo de seus conteúdos e, consequentemente, de sua aplicabilidade prática. Portanto, está definitivamente justificada a total relevância da capacitação em LIBRAS para os que atuam na área de Saúde, desde a recepcionista até o médico, face às necessidades de comunicação entre o profissional e os pacientes surdos, otimizando a interação e a troca de informações, o que vem possibilitar uma assistência mais humanizada, mais resolutiva. Trabalhando assim, com primazia, o princípio básico do Sistema Único de Saúde, que é o de atender a todos conforme suas particularidades, especificidades, expectativas e necessidades.
\end{abstract}

Com essa mudança paradigmática nos cursos de formação em fonoaudiologia, novos olhares sobre a surdez começam a ser instituídos no processo reabilitador do Surdo oferecendo para o trabalho do fonoaudiólogo uma atuação que vai na contramão da histórica concepção reabilitadora dos Surdos. Para muitos, esses sujeitos passam, a partir dessa nova perspectiva, a ser considerados como sujeitos diferentes, e não mais como deficientes. O fonoaudiólogo, então, tem sido, com isso, deslocado do lugar histórico e ideológico de "normalizador" desse sujeito aos padrões ouvintes para o de que 
poderá proporcionar os primeiros contatos deste sujeito com a língua de sinais. Mudança que também afeta a abordagem e o acolhimento das famílias de crianças com diagnóstico de deficiência auditiva que nunca tiveram contato com Surdos usuários desta língua. Essas mudanças impulsionaram um novo pensamento sobre o sujeito Surdo e sobre o atendimento fonoaudiológico nos dias atuais.

Atualmente, no Brasil, poucos trabalhos se debruçaram sobre a atuação fonoaudiológica com sujeitos Surdos, a partir de uma perspectiva socio antropológica. Podemos citar Moura et al. (2007) que se preocuparam em demonstrar que a atuação fonoaudiológica ultrapassava a mera administração de técnicas e que fazia parte da atuação do fonoaudiólogo, dentre outros aspectos, a questão relacionada a política de identidade como defendido por Ciampa (2002). E Nascimento (2008) que se preocupou em compreender como os fonoaudiólogos compreendiam a cultura Surda e como a contemplavam em seu trabalho clínico. Esses dois trabalhos pioneiros mostram que há a necessidade de se expandir as pesquisas nessa área. Afinal, com um decreto que estabelece mudanças estruturais importantes, como o trabalho de português como segunda língua, alguns pontos necessitam ser muito bem compreendidos se desejamos que uma atuação coerente seja proposta.

Uma forma de se fazer isso é escutar dos sujeitos Surdos suas representações a respeito da atuação fonoaudiológica e isso significa dar lugar para que esses indivíduos possam contar suas histórias de reabilitação a partir de suas próprias narrativas. Strobel (2008) acentua esta questão:

[...] a história do povo surdo mostra que por muitos séculos de existência, a pedagogia, as políticas e muitos outros aspectos próprios do povo surdo têm sido elaborados sempre sob o ponto de vista dos ouvintes e não dos surdos que, quase sempre, são ignorados, desvalorizados enquanto sujeitos e profissionais que podem contribuir a partir de suas capacidades essenciais e de sua diferença: do ser surdo (p. 41).

Propiciar a esses sujeitos espaço para falarem do processo terapêutico a qual foram submetidos pode possibilitar a construção de um novo parâmetro de atuação fonoaudiológica na clínica da surdez. Foi nesse sentido que a pesquisa aqui descrita buscou escutar, pela e na narrativa dos próprios indivíduos submetidos ao processo terapêutico de reabilitação fonoaudiológica, como a ação desse profissional configurou-se até então. Nesse sentido, o objetivo deste trabalho foi compreender qual é a representação que os indivíduos Surdos têm da atuação fonoaudiológica e quais as suas sugestões para que esse processo possa ser mais efetivo.

\section{METODOLOGIA}

O presente trabalho caracteriza-se por um estudo qualitativo exploratório resultante de uma pesquisa de Iniciação Científica aprovada pelo Comitê de Ética da Pontifícia Universidade Católica 
de São Paulo sob o número de protocolo 328/2008 e subsidiada pelo fomento do Centro de Ensino e Pesquisa da Pontifícia Universidade Católica de São Paulo (CEPE/PUC-SP). Esta pesquisa faz parte de um projeto único em que também foi investigada a representação dos sujeitos surdos em relação à educação.

Foram filmados dezesseis sujeitos Surdos com idade entre vinte e cinquenta anos que frequentaram terapia fonoaudiológica e que fazem uso tanto da língua portuguesa oral como da Língua Brasileira de Sinais (Libras), ou então das duas línguas para comunicação. A coleta de dados deu-se por meio de entrevistas, pois consideramos este método de coleta de dados uma forma já consagrada de se obter informações sobre o objeto de pesquisa, pois, segundo Lüdke e André (1986, p. 33-34) ela "[...] permite a captação imediata e corrente da informação desejada, praticamente com qualquer tipo de informante e sobre os mais variados tópicos".

O material usado para a coleta de dados foi um questionário semi-aberto com temáticas sobre o processo terapêutico fonoaudiológico, atuação do fonoaudiólogo junto à família e representações sobre a fala e o uso do aparelho auditivo. Os sujeitos foram filmados e suas entrevistas foram traduzidas para o português. Embora o corpus seja composto de discursos de sujeitos com duas modalidades linguísticas de comunicação, todos os entrevistados usam a Língua Brasileira de Sinais (Libras) ora como língua principal de seus discursos, ora como língua de apoio para a oralidade e os pesquisadores, por possuírem conhecimento e fluência em ambas as línguas, realizaram traduções da Libras para a Língua Portuguesa escrita.

As entrevistas foram precedidas pelas informações dos objetivos, métodos de coleta e análise, possíveis riscos, benefícios e de que os sujeitos poderiam desistir de participar da coleta em qualquer momento no período de vigência da pesquisa. Os sujeitos assinaram um termo de consentimento livre esclarecido proposto pelo Comitê de Ética em Pesquisa da Pontifícia Universidade Católica de São Paulo autorizando a divulgação das informações fornecidas nas entrevistas. As entrevistas foram analisadas a partir da proposta de Bardin (1977) que propõe a organização da análise em torno de cinco pólos cronológicos: a pré-análise, a exploração do material, o tratamento dos resultados, a inferência e a interpretação.

Durante o relato dos resultados e da discussão os sujeitos entrevistados foram identificados por números para salvaguardar suas identidades, conforme explicitado para os sujeitos participantes antes da entrevista e colocado no termo de consentimento livre e esclarecido. 


\section{RESULTADOS E DISCUSSÃO}

Encontrar sujeitos para participar desta pesquisa foi uma tarefa árdua. Embora a Libras seja uma língua de modalidade gestual-visual-espacial e a sua produção discursiva se dê no espaço tornando, portanto, o discurso visível para quem está próximo dos interlocutores, a exposição para uma câmera intimidou os voluntários, fazendo com que alguns desistissem frente ao cenário montado para a coleta de dados com a justificativa de que expor sua história perante uma câmera não seria algo fácil a se fazer. Além disso, muitos também não estavam acostumados a serem filmados e por isso sentiram-se constrangidos em estar diante de uma câmera. O questionamento sobre o processo de terapia fonoaudiológica e a lembrança por parte desses sujeitos destes momentos de suas vidas deixaram alguns dos entrevistados intimidados em falar a respeito de sua infância.

No projeto inicial considerou-se que seriam filmados vinte sujeitos surdos com idade entre vinte e cinquenta anos que fizessem uso tanto da língua portuguesa oral como da Libras como forma de comunicação, ou então das duas línguas. Porém, pelos motivos supracitados foram entrevistados dezesseis sujeitos. É importante salientar esse fato, pois ele demonstra o quanto o processo terapêutico pode ter sido traumatizante para muitos dos sujeitos procurados, demonstrando que, para esses, na época de sua infância e juventude, a terapia fonoaudiológica pode não ter levado em conta aspectos importantes a condição visual para a aquisição de uma língua e a possibilidade do uso da língua de sinais. Entendemos, com isso, que a compreensão de aspectos relacionados à condição surda de estar no mundo pode ter faltado aos profissionais que lidaram com os Surdos entrevistados (MIORANDO, 2006). Isso não representa uma crítica ao atendimento fonoaudiológico em si, mas é a constatação de que as práticas sociais dependem de variáveis históricas e culturais que determinam a forma pela qual elas serão exercidas (CIAMPA, 1990).

Todos os sujeitos entrevistados declararam terem sido submetidos a processo terapêutico fonoaudiológico, tanto dentro da escola especial na qual estudavam, em sessões individuais particulares ou em serviço público de saúde. Os dezesseis entrevistados declararam ser fluentes em Libras. Porém um dos entrevistados declarou não usá-la em sua comunicação diária. Um sujeito afirmou saber falar algumas palavras em língua portuguesa, porém não possui uso funcional dessa fala. Os catorze sujeitos restantes usam a Libras e a fala em sua comunicação cotidiana com sujeitos Surdos ou ouvintes. Do total dos sujeitos entrevistados, catorze usaram a Libras junto com a fala no momento da entrevista, enquanto os dois restantes usaram a Libras sem o apoio da linguagem oral.

A análise dos dados mostrou que quando questionados sobre seu processo de terapia fonoaudiológica, os sujeitos entrevistados apresentaram respostas que variaram de momentos de sofrimento em que precisavam realizar exercícios fonoarticulatórios para aprender a falar até como o 
momento em que podiam conversar com alguém que tinha uma escuta direcionada a eles, não somente para que eles pudessem aprender uma modalidade linguística para comunicação, mas para que pudessem falar de seus conflitos diários vivenciados, muitas vezes, pelas barreiras de comunicação na família.

\footnotetext{
"Gostava de ir na fono sim, mas eu sofri muito. Porque eu tinha que falar muito e cansava, eu ficava muito cansada”. (15)

"No começo eu não gostava tanto, mas depois eu comecei a perceber que eu precisava e que era necessário fazer fono, ai eu comecei a gostar e não queria sair de lá. Ela me ajudava e ao mesmo tempo era terapia, ela me ajudava assim com o desabafo. Foi muito bacana essa coisa de fazer fono, eu adorava" (2)
}

Pode-se perceber, por esse último discurso, que o trabalho fonoaudiológico expandia suas fronteiras técnicas, possibilitando que aspectos de constituição do sujeito pudessem ser ventilados e trabalhados. Verifica-se aqui uma atuação mais global e que tende a perceber o indivíduo nas suas peculiaridades, havendo não só um olhar para a alteração biológica, a deficiência auditiva, mas para além disso, uma escuta para o sujeito pleno que se apresentava para aquela clínica. Segundo Moura et al. (2006) o trabalho fonoaudiológico deve contemplar mais do que a aplicação de técnicas, “[...] o trabalho com Surdos tem expressão mais ampla do que o trabalho técnico. Ele deve fornecer coerência, para que o Surdo possa aprender sobre o mundo e sobre si mesmo, deve propiciar a produção do mundo vivido e sentido" (p. 207)

Geralmente, todos os sujeitos com diagnóstico de deficiência auditiva são submetidos ao processo de reabilitação fonoaudiológica para um trabalho de aquisição e desenvolvimento de linguagem. No cenário da atuação fonoaudiológica com sujeitos surdos existem abordagens diversas de reabilitação que estão ligadas a concepções prévias do que é linguagem e de quem é o surdo. Historicamente a clínica fonoaudiológica exerceu papel de reabilitação das vias auditivas deficientes para que esses sujeitos pudessem adquirir a língua oral, possibilitando, assim, que eles se tornassem "ouvintes". Esse trabalho recebeu respaldo do desenvolvimento científico e tecnológico que propiciou dispositivos terapêuticos para a reabilitação de pessoas com deficiência auditiva, voltados a minimizar os efeitos da surdez, como aparelhos de amplificação sonora individuais sofisticados, implante coclear, softwares para o desenvolvimento de fala, etc. (NASCIMENTO, 2002).

O uso dessas tecnologias, tanto do aparelho auditivo como do implante coclear, também aparece no discurso dos entrevistados e a representação desses dispositivos variam. Porém, todos os sujeitos entrevistados declaram que o aparelho auditivo auxilia muito mais na percepção de ruídos do que na compreensão da fala. 


\begin{abstract}
"Usava bastante tempo, eu comecei a usar com três anos e eu sempre tirava e colocava o aparelho, não me lembro muito. Eu decidi se eu ia usar ou não quando eu percebi que me atrapalhava muito e eu não conseguia entender as coisas e minha cabeça doía, mas eu gostava de usar o aparelho, principalmente pra escutar minha voz" (10).

"O aparelho não deixa a gente ouvinte, isso não, é bom que me ajuda a sentir, por exemplo, vamos imaginar que sem o aparelho se houver algum barulho que assusta, pra mim é bom ficar sabendo o que tá acontecendo, quem usa o aparelho ajuda um pouco a sentir e prestar a atenção no barulho" (5).

"Na comunicação não, não dava pra ouvir perfeitamente, só ajudava com os barulhos, eu acho que eu não preciso usar aparelho” (7).
\end{abstract}

Percebe-se, a partir destes discursos, que o valor dos aparelhos auditivos deve ser redimensionado, pois ainda para muitos profissionais eles são considerados como um instrumento que permitirá a anulação da surdez. Não queremos dizer que os Aparelhos Sonoros de Amplificação Sonora Individual (AASI) não devam ser indicados ou utilizados, mas que a sua verdadeira utilidade deve ser redimensionada, não apenas pelos profissionais, mas principalmente nas informações passadas aos pais que muitas vezes colocam toda a esperança de desenvolvimento de seus filhos Surdos no aparelho auditivo.

Outro elemento presente na fala dos sujeitos Surdos em relação ao uso do aparelho auditivo são as representações que a própria comunidade Surda possui do uso desse aparato tecnológico e de quem o usa.

\footnotetext{
“Já usei, comecei com 5 anos mais ou menos, até os 11, não lembro direito. Mas eu voltei a usar em 1998, mas eu sentia um pouco de vergonha, as pessoas ficavam me olhando e também os outros surdos ficavam me acusando por que eu tava usando. Mas eu não escutava bem com eles, escutava um pouco só, então eu tirava" (1)

"Na verdade eu não gostava muito de usar, eu me recusava usar, mas eu sabia que era importante usar o aparelho pra ajudar você a perceber a voz, a sua fala então eu tirava, eu não gostava tanto, mas eu sei que é importante usar. Hoje eu não uso porque eu não me sinto bem usando aparelho, eu to bem assim, eu sei que eu tenho minha perda moderada e tal, consigo ouvir algumas coisas sim, mas com o aparelho eu ouço bem mais" (2).
}

A concepção por parte dos Surdos de que o aparelho auditivo transforma o sujeito em ouvinte emerge da ideia de que ele, o aparelho, é o aparato externo que possibilita para o sujeito que vive em silêncio a entrada do som descaracterizando a identidade enquanto Surdo, que é marcada, dentre muitos fatores, pela própria ausência da audição. Perlin (1998) define identidade Surda como aquela em que os sujeitos Surdos fazem uso da experiência visual para estarem no mundo e que fazem diferentes usos de comunicação na modalidade viso-espacial. Para esses sujeitos, submeter-se a um processo de protetização auditiva significa ferir sua identidade Surda, dando acesso a um estímulo que para eles, até então, é algo entranho: o som. 
Na clínica fonoaudiológica do trabalho com a surdez em uma perspectiva de reabilitação aural a protetização é considerada como fator primordial para a aquisição da linguagem oral. Segundo Balieiro e Ficker (1997) as propostas de reabilitação auditiva em crianças com deficiência na audição têm por objetivo oferecer à criança as melhores oportunidades para desenvolver suas habilidades linguísticas para que possa ser linguisticamente competente na língua de sua família. Para alguns dos Surdos entrevistados essa é uma marca não desejada, seja porque explicita a surdez que de outra forma seria "invisível”, seja porque é um artefato que a comunidade Surda rejeita e pertencer ao grupo é muito importante para eles como o é para todos os indivíduos (GOFFMAN, 1988).

Apesar do discurso de alguns sujeitos apresentarem discrepância com relação ao atendimento fonoaudiológico, é possível considerar que as dificuldades enfrentadas pelos surdos (citadas acima) foram menores do que os benefícios atingidos. Afinal, apesar do discurso acadêmico e ideológico que se encontra a respeito da não necessidade de fala para os Surdos (SKLIAR, 1997, 1998; QUADROS, 1997; LULKIN, 1998), parece que a fala tem uma importância real em suas vidas, não para se constituírem ou para se configurarem como ouvintes, o que já foi visto como impossível de ser atingido (MOURA, 2000), mas como forma de comunicação e de interação no mundo ouvinte.

\footnotetext{
"Foi importante na minha vida. Por que foi bom para aprender a falar para conviver com as pessoas e se comunicar com elas, por exemplo, no meu trabalho, na faculdade, na escola..." (6)

"E para mim, o motivo de eu amar minha fono foi porque ela me ajudou muito a me comunicar com as pessoas no mundo, na sociedade e as coisas ficaram mais claras pra entender, e eu agradeço muito a minha fono pelo trabalho que ela fez comigo, não quero que o número de fonoaudiólogos diminua, mas que cresça para continuar a apoiar o surdo" (11).

"Eu aprendi uma série de coisas, mas ajudava a perceber as coisas, ajudava a perceber o que tava acontecendo comigo, os problemas, a dificuldade de escolhas, eu acho que me ajudava muito e ajudou muito com a família” (2).
}

A família e a escola, representando o mundo dos ouvintes, se mostram como os lugares beneficiados com a possibilidade do uso da fala que de uma forma geral é super estimada pelos ouvintes como fator seja de "normalização" ou de aquisição de conhecimentos (SVARTHOLM, 2008), sendo colocada no seu devido lugar pelos Surdos nesse trabalho, ou seja, no lugar de permitir a interação e o contato social.

As formas de trabalho dos fonoaudiólogos com os sujeitos entrevistados também foram lembrados com detalhes. O uso de sinais no processo de terapia fonoaudiológica foi apresentado como elemento primordial no trabalho com o Surdo, pois para os entrevistados o conhecimento da língua de sinais por parte desses profissionais auxiliaria o trabalho do fonoaudiólogo com o Surdo para o aprendizado da linguagem oral. Dessa forma a fala seria considerada como uma segunda língua para 
esse sujeito, e não como constitutiva de sua subjetividade, corporificando em sua atuação uma concepção bilíngue de trabalho em que o ensino de uma segunda língua só poderá ser feita quando a primeira língua, a língua materna, estiver totalmente adquirida.

Podemos perceber que a terapia fonoaudiológica aparece nos discursos como um período importante na vida dos sujeitos Surdos no momento em que eles precisavam usar uma língua para se comunicar, no apoio na comunicação no seio familiar e nos momentos em que precisavam de alguém que lhes direcionasse uma escuta para os problemas em suas vidas. O fonoaudiólogo aparece como o único profissional habilitado para possibilitar-lhe o aprendizado da linguagem oral e, embora o processo de terapia fonoaudiológica e aprendizagem da fala tenha sido, em alguns casos, um período difícil e intenso é unânime a concepção do aprendizado da fala como fator importante para a convivência com pessoas ouvintes.

\begin{abstract}
"Eu gostava de ir na fono, porque eu não sou contra a fala, eu acho bom ter a possibilidade de usar os sinais e a fala quando eu quiser usar. [...] Informações sobre estações de metrô, eu até sei algumas palavras, elas me ajudam, mas eu preciso treinar mais. Eu não sou contra a fala ou contra os sinais. Infelizmente, atualmente há muita discussão sobre isso, acho que as pessoas tem que ser livres pra escolher o que elas vão usar, é essa minha opinião" (1).
\end{abstract}

"Eu sempre ia para ajudar na fala e na leitura também, era bom para me ajudar a me comunicar com as pessoas no trabalho e em outros lugares também e ajudar outros surdos também, por exemplo, se tem algum surdo que não sabe se comunicar falando eu ajudo a interpretar também, é importante também" (3).

Mais uma vez verificamos que a fala aparece para os sujeitos entrevistados como mais uma possibilidade de comunicação com pessoas que desconhecem a língua de sinais. Essa posição pode ser marcada como uma mudança política na comunidade Surda. A partir do momento que esses indivíduos se deparam com a realidade das barreiras comunicacionais em situações cotidianas como em seus locais de trabalho, por exemplo, percebem que há a necessidade de usar a comunicação da comunidade majoritária.

Isso é resultado de um interessante movimento social em que a sociedade que é levada a ter em seu convívio nas diferentes esferas sociais sujeitos Surdos, possibilita que eles possam se ver como sujeitos produtivos e participantes no âmbito do trabalho e perceberem a fala como elemento integrante dessa nova realidade. Por sua vez, a sociedade, percebendo as possibilidades intelectuais e produtivas dos Surdos, os recebe de uma forma menos preconceituosa, permitindo que eles possam ocupar um lugar que não o do deficiente.

Essa reciprocidade aparece nos discursos aqui analisados e aponta para a importância de um mundo inclusivo em que ambas as partes devem se adaptar para que o que é desejado - um mundo justo para todos - possa vir a acontecer. É verdade que a adaptação das diversas instâncias sociais para receber os sujeitos Surdos em sua língua determinada legalmente vem acontecendo lentamente, 
mas ela possibilita a criação da demanda para que essa comunidade enxergue a fala não mais como uma forma de colonização por parte dos ouvintes, conforme coloca Strobel (2008), mas como o aprendizado de outra língua para a convivência pacífica e sem barreiras na comunicação diária com a maioria ouvinte.

"Eu acho que a fala e os sinais são importantes. Se a pessoa quer falar eu falo, se quer sinais eu faço sinais junto com a fala. Eu gosto dos dois, é bom pra treinar a fala e os sinais, eu não tenho preconceito com um ou com o outro" (14).

"Imagina, no mundo $80 \%$ são ouvintes e 20\% são surdos, preciso falar, fazer o que. Para conseguir emprego, escola, amigos, tudo. Ter aprendido a falar valeu a pena” (13).

"No trabalho, porque lá não tem pessoas que não sabem sinais, fazem mímica, ou então poucos sinais, mas a fala é o principal, as pessoas já se acostumaram com a minha voz e minha fala, são poucas as pessoas que não me entendem lá, tem alguns que são mais difíceis pra conversar [...]" (8).

O fonoaudiólogo, enquanto único profissional habilitado para realizar um trabalho de desenvolvimento de linguagem oral com sujeitos Surdos, deve ater-se a essa nova demanda que se instaura no cenário atual: a modalidade oral da língua majoritária como uma das faces da segunda língua para o Surdo. Moura (2000) afirma que se a fala continuar a ser vista como elemento básico para a aceitação social e para a educação, os resultados não poderão diferenciar-se do que tem sido até então: fracasso na educação e na possibilidade de ser sujeito.

A linguagem oral, a partir das respostas dos sujeitos entrevistados, aparece não como um suplemento para a língua de sinais, que na maioria das respostas dos sujeitos entrevistados é a primeira língua, ou como elemento de auto aceitação enquanto sujeito, mas sim como uma necessidade para que ele possa instaurar-se enquanto cidadão bilíngue em uma sociedade plurilinguística e multicultural (MOURA; NASCIMENTO, 2009).

Nessa nova realidade brasileira em que a Libras é reconhecida legalmente como língua oficial da comunidade Surda e do aumento de pesquisas nas áreas de educação, surdez, língua de sinais e inclusão, a linguagem oral descentraliza-se no processo educacional dos Surdos, tal como foi colocada no Congresso de Milão no ano de 1880, e passa a ser colocada como mais uma possibilidade de integração social do sujeito Surdo no discurso dos próprios Surdos, como se vê abaixo:

\footnotetext{
"Depois que eu entrei na faculdade tive que aprender a falar mais, porque não tinha surdo, eram todos ouvintes e eu tinha que me esforçar pra falar com o grupo. Eu comecei a fazer fono dentro da faculdade também, porque eu faço comunicação e artes do corpo e tem uma professora que é fonoaudióloga e trabalha com a voz e a gente estudava voz, e eu me soltava e falava na aula e me desenvolvi" (7).
} 
O que se pode perceber como modificação nesse discurso é a inversão da demanda para o aprendizado da linguagem oral: é o próprio Surdo que deseja desenvolver a fala e que encontra no seu ambiente educacional um espaço para realizar o que passou a almejar: uma comunicação oral que lhe permita uma inserção no mundo dos ouvintes.

Outro elemento presente nos discursos dos sujeitos entrevistados foi a ausência da atuação do fonoaudiólogo junto à família, ao menos no discurso dos mesmos, como se pode observar abaixo. Essa atuação é fundamental para o desenvolvimento de linguagem de crianças surdas independente da abordagem de reabilitação utilizada pelo fonoaudiólogo no processo terapêutico, pois como afirmam Holzheim et al. (1997, p. 418) “a família é um sistema primário que gera alimento para o desenvolvimento de todos os seus membros. Constitui-se como o centro da vida da criança e, por isso, assume uma posição crítica para o seu desenvolvimento”.

\footnotetext{
"Sempre sozinho, nunca entrava comigo, só entrava se fosse outro assunto, mas não me acompanhava essa coisa de trabalhar junto comigo, não" (2).

"Eu comecei a falar com 5 anos, mas antes eu falava pouco. Como não tinha comunicação entre eu e minha mãe, ela me levou na fono para aprender a falar e treinar a voz, mas era muito difícil e não adiantou muito, então a minha mãe me incentivava a falar. Com dois anos eu comecei a usar aparelho, mas era muito barulho, muito confuso, mas minha mãe falava que eu precisava ouvir e treinar a audição e depois com cinco anos eu comecei a falar algumas palavras, a fono também ajudava um pouco e minha mãe também, mas eu aprendi mais com a minha mãe" (4).
}

Três dos entrevistados declaram lembrar que o fonoaudiólogo trabalhava junto com a família e que autorizavam a entrada do responsável, geralmente a mãe, a entrar na sala de terapia para acompanhar as sessões. Os outros sujeitos declaram não saber ou não lembrar se o fonoaudiólogo trabalhava ou não com a família.

\footnotetext{
"Mas no começo minha mãe não entrava na sala, porque eu precisava aprender com a fono, porque eu tava acostumado a ficar junto com a minha mãe e depois me acostumei a ficar com a fono, porque ela me ensinava as coisas" (6).
}

O trabalho com a família realizado pelo fonoaudiólogo considera que é na família que esse sujeito encontra suporte emocional e ainda, conforme afirma Passos (2002, p. 55), “[...] permite a origem e estruturação do sujeito e de sua linguagem, a família continuará por todas as etapas da vida referenciando esse sujeito em seu permanente processo de transformação".

Na clínica da surdez, a atuação junto a família é fundamental para o processo de aquisição de uma língua pela criança Surda, seja na tentativa de suprir a ausência da audição em uma reabilitação aural, ou no trabalho que considera a língua de sinais como primeira língua da criança surda e no seu aprendizado pela família. 
Nos discursos dos entrevistados foi possível notar que a questão da família pareceu ser desconsiderada no processo de atuação fonoaudiológica. O olhar para a família, por parte desse profissional, faz-se necessário não somente pela importância que essa instituição social tem na vida do sujeito para a formação de sua identidade, mas também porque a identificação enquanto ser falante de uma língua acontece nas relações biunívocas estabelecidas, primeiramente, entre os pares no seio familiar. Por esse motivo é de suma importância, na atuação fonoaudiológica em uma abordagem bilíngue, que os membros da família aprendam a língua de sinais para comunicar-se com a criança Surda.

$\mathrm{Na}$ narrativa dos sujeitos Surdos sobre a sua história com a Fonoaudiologia fica expressa a demanda para um trabalho envolvendo o aprendizado da oralidade, mas não como algo que lhes defina como ouvinte, mas em uma perspectiva bilíngue. Dessa forma, a língua portuguesa na modalidade oral deveria ser trabalhada a partir das possibilidades de aprendizado de cada um, com uma metodologia de trabalho que englobasse sua língua materna e a considere como fundante no aprendizado de outras línguas.

Outro aspecto importante de ser salientado é a mudança de paradigmas em que os surdos, que antes se opunham à oralidade, se percebem beneficiados com ela, não para serem comparados aos ouvintes, mas porque a fala lhes oferece melhores condições de transito pela comunidade ouvinte. Isso demonstra que os Surdos saíram do papel de receptores e não falantes de sua própria realidade, para passarem a refletir e ter um discurso próprio que reflete suas necessidades.

\section{CONCLUSÃO}

A partir dos dados analisados percebeu-se na narrativa dos sujeitos entrevistados que o fonoaudiólogo é o profissional habilitado que possibilita aos surdos o aprendizado da linguagem oral. O processo terapêutico a qual foram submetidos foi lembrado como o momento em que puderam aprender mais uma forma de comunicação, haja vista que a língua de sinais, na maioria dos casos, foi adquirida em espaço pedagógico nas escolas especiais ou bilíngues que estudaram.

Os sujeitos aqui entrevistados que usam a Libras como primeira língua e que aprenderam a falar em terapia fonoaudiológica consideram que a linguagem oral facilita sua comunicação com as pessoas ouvintes que não sabem comunicar-se em língua de sinais em situações cotidianas. Os sujeitos entrevistados que foram oralizados em processo terapêutico e depois aprenderam a língua de sinais consideram também que a fala em sua comunicação cotidiana é importante, porém não essencial- 
A representação dos surdos em relação ao trabalho fonoaudiológico aparece na narrativa dos sujeitos surdos submetidos ao processo de reabilitação como a oferta da possibilidade da aprendizagem da linguagem oral para que estes possam viver em meio a maioria ouvinte sem barreiras comunicacionais. Isso demonstra uma mudança sobre a fala nas concepções sobre a surdez. Primeiro, na concepção socio antropológica que defendia a fala como elemento não necessário ao Surdo. E, segundo, na concepção oposta, a clínico terapêutica, de que só a fala possibilita a esse sujeito autonomia comunicacional. A fala aparece aqui em um entre-lugar, isto é, ela não é elemento descaracterizador do Surdo, mas, ao mesmo tempo, não deve assumir um lugar de prestígio no trabalho clínico.

É importante frisar que o número reduzido de sujeitos que se propuseram a ser entrevistados demarcou o quanto a prática fonoaudiológica com os Surdos pode ter causado marcas na sua identidade enquanto Surdo, fazendo com que os sujeitos abordados recusassem a falar sobre esses momentos em suas vidas devido às lembranças desagradáveis que eles têm desse período. Esse elemento aponta para a necessidade da ampliação de pesquisas com a temática das representações dos sujeitos Surdos sobre a prática fonoaudiológica, pois a partir das narrativas daqueles que a fonoaudiologia historicamente nomeou "deficientes auditivos", percebe-se que, na atualidade, essa deficiência na audição não os descaracteriza enquanto sujeitos. Não há, com isso, a necessidade de uma reabilitação auditiva a priori para uma aproximação do estereótipo de ouvintes para que sejam considerados cidadãos como há muito tempo vêm sido pregado e promovido na fonoaudiologia brasileira. O que se vê, aqui, é a surdez como um traço de identidades tornando os Surdos membros de uma minoria linguística que deseja instaurar-se enquanto comunidade bilíngue.

Essa mudança de perspectiva social e histórica sobre o que significa "ser Surdo", sobre o status de uso da língua de sinais em relação à língua oral e a mudança da prioridade da aprendizagem da oralidade, impacta diretamente as práticas fonoaudiológicas contemporâneas na clínica da surdez. Isto traz a demanda de uma revisão, por parte dos fonoaudiólogos, do que significa diagnosticar a surdez, acolher a família e reabilitar o sujeito. Se a fala, tomada aqui pelos entrevistados como algo importante, mas não essencial, configura o trabalho do fonoaudiólogo com os Surdos, nessa nova perspectiva, não seria ela muito mais uma opção linguística frente às outras possibilidades de línguas a serem escolhidas pelos Surdos do que uma prática reabilitadora? Faltaria, nesse sentido, a fala ao Surdo para que ele se torne sujeito? No século XXI, na era da afirmação das diferenças, os Surdos podem ser o que quiserem pela língua que escolherem se comunicar. A escolha é deles. Resta à clínica fonoaudiológica da surdez, então, amoldar suas práticas às novas realidades e demandas apresentadas pelos surdos enquanto comunidade linguística, minoritária, autônoma e cidadã. 


\section{REFERÊNCIAS}

BALEIRO C.R., FICKER L.B. Reabilitação aural: a clínica fonoaudiológica e o deficiente auditivo. In: LOPES FILHO O. C., (Org). Tratado de fonoaudiologia. São Paulo: Roca; c1997. p. 311-325.

BARDIN, L. Análise de Conteúdo. Lisboa: Edições 70, 1977.

BERBERIAN, A. P. Fonoaudiologia e educação: um encontro histórico. São Paulo: Plexus, 1995.

BRASIL. Ministério da Educação e Cultura. Centro Nacional de Educação Especial - CENESP. Proposta curricular para deficientes auditivos. (nove volumes: 1a série, 2a série, 3a série, 4a série, 5a série, 6a série, 7a série, 8a série e o manual).Brasília, DF: MEC, 1979.

BRASIL. Lei 10.436, de 24 de abril de 2002. Dispõe sobre a Língua Brasileira de Sinais (LIBRAS) e dá outras providências. Disponível em:

$<$ http://www.planalto.gov.br/ccivil_03/LEIS/2002/L10436.htm> Acesso em: 20 de janeiro de 2010.

. Decreto 5.626, de 22 de dezembro de 2005. Regulamenta a Lei $\mathrm{n}^{\circ} 10.436$, de 24 de abril de 2002, que dispõe sobre a Língua Brasileira de Sinais - Libras, e o art. 18 da Lei $\mathrm{n}^{\circ} 10.098$, de 19 de dezembro de 2000. Disponível em: <http://www.planalto.gov.br/ccivil_03/_ato20042006/2005/decreto/d5626.htm> Acesso em: 20 de janeiro de 2010.

CIAMPA, A. C. Políticas de Identidade e Identidades Politicas. Texto elaborado a partir de apresentação em mesa redonda no I Congresso Brasileiro Psicologia: Ciência e Profissão, realizada em 03/09/2002.

. A Estória do Severino e a história da Severina. São Paulo: Editora Brasiliense, 1990.

COUTINHO, A. E. Surdo, Professor de Surdos - Perspectiva Histórica e Situação Atual. In:

MOURA, Maria Cecília de; VERGAMINI, Sabine Antonialli Arena; CAMPOS, Sandra Regina Leite de. Educação para surdos: práticas e perspectivas. São Paulo: Santos Editora, 2008.

GOFFMAN, E. Estigma: notas sobre a manipulação da identidade deteriorada. Rio de Janeiro, Editora Guanabara, 1988.

GUARINELLO, A. C. et al. A disciplina de Libras no contexto de formação acadêmica em fonoaudiologia. Rev. CEFAC, vol.15 no.2, São Paulo mar./abr. 2013.

Disponível em: http://dx.doi.org/10.1590/S1516-18462012005000047 
HOLZHEIM, D. C. P. M; LEVY, C. C. A. C; PATITUCCI, S. P. R; GIORGI. S. B. Família e Fonoaudiologia: o aprendizado da escuta. In FILHO, O. T. (org.) Tratado de Fonoaudiologia. São Paulo: Rocca, 1997.

LÜDKE, M.; ANDRÉ, M. Pesquisa em educação: abordagens qualitativas. São Paulo: EPU, 1986.

LULKIN, S. O discurso moderno na educação dos surdos: práticas de controle do corpo e a expressão cultural amordaçada. In: Skliar, Carlos. (Org.) A Surdez: um olhar sobre as diferenças. Porto Alegre: Editora Mediação., 1998.

MIORANDO, T. M.. Formação de profissionais - mais professores para a escola sonhada. In: QUADROS, Ronice Muller. (Org.). Estudos Surdos I. Petrópolis, RJ: Arara Azul, 2006.

MOURA, M. C. O Surdo: Caminhos para uma Nova Identidade, Rio de Janeiro, Revinter Editora, 2000.

. LODI, A. C. B.; HARRISON, K. M. P. A História e a Educação dos Surdos In: LOPES FILHO, O. (Org.) Tratado de Fonoaudiologia. São Paulo: Ed. Tecmedd, 2006.

. NASCIMENTO, M. V. B. Relações de poder envolvendo a surdez, 2009. Disponível em:

$\overline{<\mathrm{http}}$ //www.ifono.com.br/ifono.php/relacoes-de-poder-envolvendo-a-surdez $>$

NASCIMENTO, V.; BRAIT, B. Reflexões dialógicas sobre a clínica de linguagem. In: MONTENEGRO, A. C. A.; BARROS, I. R.; AZEVEDO, N. S. G. (Orgs) Fonoaudiologia e Linguística: teoria e prática. Curitiba: Editora Appris, 2016.

NASCIMENTO, M. V. B. A Representação da Cultura Surda no Universo Fonoaudiológico [Iniciação Científica] São Paulo: PUC SP, 2008.

NASCIMENTO, L. C. R. Fonoaudiologia e Surdez: uma análise dos percursos discursivos da prática fonoaudiológica no Brasil. [Dissertação]. Campinas: UNICAMP, 2002.

PADDEN, C.; HUMPHIRES, T. Deaf in America. Massachusetts: Harvard University Press, 1988.

PASSOS, M. P. (2002). Família: o que muda e o que permanece em diferentes configurações. Cadernos de Psicologia, 12 (1), 31-43.

PERLIN, G.. Identidades Surdas. In: SKILIAR, Carlos. (Org.). A surdez: um olhar sobre as diferenças. Porto Alegre: Mediação, 1998. 
QUADROS, R. M. Educação de Surdos: a aquisição da linguagem. Porto Alegre: Artmed, 1997.

SKLIAR, C. (org.) Educação e Exclusão - Abordagens Sócio-Antropológicas em Educação Especial. Porto Alegre. Editora Mediação, 1997.

. Um Olhar Sobre o Nosso Olhar Acerca da Surdez e as Diferenças In : Skliar, C. Um Olhar

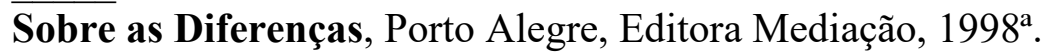

. Bilinguismo e Biculturalismo: uma análise sobre as narrativas tradicionais na educação dos surdos. Revista Brasileira de Educação. São Paulo: ANPEd, 1998b.

SOUZA, M T.; PORROZZI, R. Ensino de Libras para os Profissionais de Saúde: Uma Necessidade Premente. Revista Práxis, ano I, no 2 - agosto 2009. Disponível em:

http://web.unifoa.edu.br/praxis/numeros/02/43.pdf

STROBEL, K. As imagens do outro sobre a cultura surda. Florianópolis: Editora da UFSC, 2008.

SVARTHOLM, K. Educação Bilíngüe para os Surdos na Suécia: Teoria e Prática. In Moura, Maria Cecília; Vergamini, Sabine Antonialli Arena; Campos, Sandra Regina Leite de. Educação para

Surdos: Práticas e Perspectivas. São Paulo: Livraria Santos, 2008.

VIEIRA, M. I. S.; MOURA, M. C.; HARRISON, K. M. P. Fonoaudiologia, Pedagogia e Surdez: Reconstruindo Picasso. In: PAVONE, S.; RAFAELI, Y. M. (Org.) Audição, Voz e Linguagem: A Clínica e o Sujeito. São Paulo: Cortez Editora, 2007.

$\begin{array}{ll} & \text { Recebido em: 29-3-2017 } \\ \text { Histórico } & \text { Revisado em: 4-10-2018 } \\ & \text { Aceito em: 25-11-2018 }\end{array}$

